\title{
Periodontitis in established rheumatoid arthritis patients: a cross-sectional clinical, microbiological and serological study
}

\author{
Menke de Smit ${ }^{*}$, Johanna Westra ${ }^{2}$, Arjan Vissink ${ }^{3}$, Berber Doornbos-van der Meer ${ }^{2}$, Elisabeth Brouwer ${ }^{2}$ and
} Arie Jan van Winkelhoff ${ }^{1,4}$

\begin{abstract}
Introduction: The association between rheumatoid arthritis (RA) and periodontitis is suggested to be linked to the periodontal pathogen Porphyromonas gingivalis. Colonization of $P$. gingivalis in the oral cavity of RA patients has been scarcely considered. To further explore whether the association between periodontitis and RA is dependent on $P$. gingivalis, we compared host immune responses in RA patients with and without periodontitis in relation to presence of cultivable $P$. gingivalis in subgingival plaque.

Methods: In 95 RA patients, the periodontal condition was examined using the Dutch Periodontal Screening Index for treatment needs. Subgingival plaque samples were tested for presence of $P$. gingivalis by anaerobic culture technique. IgA, IgG and IgM antibody titers to $P$. gingivalis were measured by ELISA. Serum and subgingival plaque measures were compared to a matched control group of non-RA subjects.

Results: A higher prevalence of severe periodontitis was observed in RA patients in comparison to matched nonRA controls (27\% versus $12 \%, p<0.001)$. RA patients with severe periodontitis had higher DAS28 scores than RA patients with no or moderate periodontitis $(p<0.001$ ), while no differences were seen in IgM-RF or ACPA reactivity. Furthermore, RA patients with severe periodontitis had higher IgG- and IgM-anti $P$. gingivalis titers than non-RA controls with severe periodontitis ( $p<0.01$ resp. $p<0.05$ ), although subgingival occurrence of $P$. gingivalis was not different.

Conclusions: Severity of periodontitis is related to severity of RA. RA patients with severe periodontitis have a more robust antibody response against $P$. gingivalis than non-RA controls, but not all RA patients have cultivable P. gingivalis.
\end{abstract}

\section{Introduction}

Several studies have demonstrated an increased prevalence of periodontitis and a higher rate of tooth loss in patients with rheumatoid arthritis (RA) in comparison with the general population in the US [1,2], Northern Europe [3-6], and Australia [7]. RA may also be more prevalent among patients with periodontitis $[4,8]$. Differences in disease criteria and methods for evaluation of periodontal status, however, form a problem in interpretation of the literature $[9,10]$.

\footnotetext{
* Correspondence: m.j.de.smit@umcg.nl

'Center for Dentistry and Oral Hygiene, University of Groningen, University Medical Center Groningen, P.O. Box 30.001, 9700 RB Groningen, The Netherlands

Full list of author information is available at the end of the article
}

Periodontitis and RA are both chronic destructive inflammatory disorders and result from deregulation of the host inflammatory response. Both conditions are potentiated by an exaggerated inflammatory response featuring an increase in local and perhaps circulating pro-inflammatory mediators, resulting in destruction of the soft and hard tissues surrounding the teeth (the periodontium) and the synovial joint [11-14]. Susceptibility is influenced by shared genetic and lifestyle factors. Both diseases are cumulative; that is, severity and loss of function increase with longer disease duration.

There are a number of postulated mechanisms by which infections can trigger autoimmune disease, but most evidence in animal models supports the idea that

\section{Biomed Central}


cross-reactive immune responses cause autoimmunity because of molecular mimicry between microbiological and self-antigens [15]. Rosenstein and colleagues [16] have hypothesized that Porphyromonas gingivalis, a major periodontal pathogen, plays a role in the pathogenesis of RA. P. gingivalis is a prokaryote that uniquely contains a peptidyl arginine deiminase enzyme [17] necessary for citrullination and can induce an immune response to citrullinated self-proteins $[16,18]$. Citrullination changes the structure and function of proteins and has been demonstrated in several physiological and pathological processes [19]. Antibodies against citrullinated proteins (ACPAs) are $95 \%$ specific and 68\% sensitive for RA $[20,21]$. These antibodies can be present several years before the clinical onset of RA [22] and are associated with a more destructive disease course than RA without detectable ACPAs [23]. Moreover, periodontitis can contribute to the total inflammatory burden by eliciting bacteremia and systemic inflammatory responses $[24,25]$. Given the observed epidemiological association and the hypotheses mentioned above, periodontitis may be regarded as a risk factor for initiation and progression of RA. At present, disease management of RA is based on early diagnosis, aggressive treatment, and regular monitoring, and disease remission is the ultimate treatment goal. To achieve this goal, reduction of total inflammatory burden is necessary. This may involve periodontal infection control in patients with periodontitis.

Studies have reported higher antibody titers against $P$. gingivalis in RA patients and a positive correlation with ACPAs [26-28], suggesting that infection with this periodontal pathogen may play a role in the risk and progression of RA. However, oral colonization by $P$. gingivalis in patients with RA is barely considered. To study whether the association between periodontitis and RA is dependent on $P$. gingivalis, we compared host immune responses in RA patients with or without periodontitis in relation to the presence of cultivable $P$. gingivalis from subgingival plaque. Because of the recent observation that the inflamed periodontium contains citrullinated proteins [29], we also investigated the presence of ACPAs in the inflammatory exudates from the gingival crevice (gingival crevicular fluid, or GCF).

\section{Materials and methods Patients \\ Patients with rheumatoid arthritis}

Established RA patients matching the inclusion criteria were consecutively recruited between March and September 2011 at the outpatient clinic of the Rheumatology and Clinical Immunology Department of the University Medical Center Groningen in Groningen. The inclusion criterion was fulfilling the American College of Rheumatology classification criteria for RA [30], and exclusion criteria were age under 18 years, edentulism, diabetes, active thyroid disease, presence of non-oral infections, present malignancy, myocardial infarction or stroke fewer than 6 months prior to the study, pregnancy including a 6-month post-partum period as well as breastfeeding and antibiotic use fewer than 3 months prior to the study. Assuming that the prevalence of periodontitis is $10 \%$ to $15 \%$ [31] and the odds ratio of periodontitis in RA is 1.8 to 2.0 [1,7], we calculated that we needed a minimum sample size of 75 patients with RA to find a difference of $12.5 \%$ in the prevalence of periodontitis by using a two-sided binomial test.

\section{Non-rheumatoid arthritis controls}

As a reference group for microbiological and serological measurements, subjects without RA were recruited from among subjects planned for first consultation at the Department of Dentistry and Oral Hygiene of the University Medical Center Groningen. The procedures of recruitment and informed consent were the same as for patients with RA. The inclusion criterion was not having $\mathrm{RA}$, and exclusion criteria were the same as mentioned for patients with RA. Non-RA controls were matched for age, gender, number of teeth, body mass index (BMI), and smoking and periodontal status. We aimed to include matched non-RA controls in a ratio of $2: 1$ (Table 1). Healthy controls were defined as subjects without periodontitis and without cultivable subgingival P. gingivalis.

\section{Control cohort for estimating prevalence of periodontitis in} the general population

The prevalence of periodontitis was assessed in subjects attending a general dental practice within the referral area (Clinic for General Dental Practice Solwerd in Appingedam, The Netherlands). This control population consisted of 420 age- and gender-matched consecutive patients in whom the Dutch periodontal screening index (DPSI) score was assessed during one year (2010). The DPSI is a validated index based on bleeding on probing, pocket probing depth, and clinical attachment loss [32]. On the basis of DPSI scores, patients were categorized as having no periodontitis (A), moderate periodontitis (B), or severe periodontitis (C). Assessment of the socioeconomic status of this group was made according to data of highest self-reported level of received education of the municipal public health service of the northeast region of Groningen [33].

\section{Ethics approval}

All participants provided written informed consent prior to study enrollment according to the Declaration of Helsinki (General Assembly October 2008), and this study was conducted with the approval of the Medical Ethical Committee of the University Medical Center Groningen (METc UMCG 2011/010). 
Table 1 Characteristics of patients with rheumatoid arthritis (RA), non-RA controls, and healthy controls

\begin{tabular}{|c|c|c|c|}
\hline & Patients with RA & Non-RA controls & Healthy controls \\
\hline Number & 95 & 44 & 36 \\
\hline Female, percentage & 68 & 57 & 56 \\
\hline Age in years $(S D)$ & $56(11)$ & $54(9.7)$ & $34(15)$ \\
\hline Current smoker, percentage & 23 & 27 & 14 \\
\hline Former smoker, percentage & 40 & 43 & 0 \\
\hline Body mass index & $25.8(4.9)$ & $25.4(4.4)$ & NA \\
\hline Number of teeth & $23.4(6.3)$ & $24.2(4.9)$ & $27.8(2.9)$ \\
\hline RA duration in years (SD) & $7.4(5.9)$ & 0 & 0 \\
\hline DAS28 (SD) & $2.4(0.93)$ & 0 & 0 \\
\hline Seropositive for lgM-RF, percentage & 53 & 0 & NA \\
\hline Seropositive for ACPAs, percentage & 71 & NA & NA \\
\hline \multicolumn{4}{|l|}{ Medication for RA, percentage } \\
\hline None & 6 & 100 & 100 \\
\hline DMARDs & 79 & 0 & 0 \\
\hline Anti-TNF $\alpha$ & 15 & 0 & 0 \\
\hline
\end{tabular}

ACPA, anti-citrullinated protein antibody; anti-TNF $\alpha$, anti-tumor necrosis factor-alpha; DAS28, disease activity score 28 tender and swollen joint count; DMARD, disease-modifying anti-rheumatic drug; IgM-RF, immunoglobulin M-rheumatoid factor; NA, not assessed; SD, standard deviation.

\section{Clinical examination of rheumatoid arthritis}

RA disease activity was measured with the Disease Activity Score 28 joint count (DAS28) [34]. Other parameters were disease duration of RA, smoking status (current, former, or never), BMI, and RA medication, including steroids and anti-tumor necrosis factor biologic agents. Assessment of the socioeconomic status was made according to highest self-reported level of received education.

\section{Clinical examination of periodontitis}

Periodontal condition was examined by using DPSI. The DPSI score was taken by a periodontist blinded for the diagnosis of RA. In the general dental practice, the DPSI score was taken by the dentist at the first visit of the patient.

\section{Sampling}

Peripheral blood and subgingival samples were obtained from the RA and non-RA controls at the day of clinical examination. Subgingival samples were taken by using sterile paper points [35]. Microbiological sampling included selection of the deepest bleeding periodontal pocket in each quadrant of the dentition on the basis of pocket probing depth measurements. If there were no bleeding periodontal pockets, mesial sites of the first molars or, in absence of a first molar, the mesial site from the adjacent anterior tooth in the dental arch was selected. Sample sites were isolated with cotton rolls, and supragingival plaque was carefully removed with curettes and cotton pallets. Subsequently, two paper points were inserted to the depth of the pocket and left in place for
10 seconds. All paper points per subject were pooled in reduced transport fluid [36] and processed for microbiological examination immediately after sampling. GCF samples were collected in the same way. The deepest non-bleeding site per quadrant was used to collect GCF to avoid blood contamination of the sample. GCF samples were discarded for further analysis if they were visibly contaminated with blood. Paper points for the GCF sample were pooled per subject in phosphate-buffered saline (PBS) with $1 \%$ bovine serum albumin. The paper points were removed after centrifuging at 28,000 $g$ for 10 minutes, and the supernatant was stored at $-20^{\circ} \mathrm{C}$ until use.

\section{Laboratory procedures}

Serum was investigated for $\mathrm{C}$-reactive protein (CRP) concentration by enzyme-linked immunosorbent assay (ELISA) (DuoSet; R\&D Systems, Abingdon, UK). IgMRF (in international units per milliliter) was measured by using an in-house validated ELISA (cutoff point for positivity: $25 \mathrm{U} / \mathrm{mL}$ ) [37]. Total IgG anti-cyclic citrullinated protein (anti-CCP) antibodies (ACPAs) (in units per milliliter) were determined by using the Phadia analyzer (Phadia Laboratory Systems, Phadia AB, Uppsala, Sweden) with an upper detection limit of $340 \mathrm{U} / \mathrm{mL}$ (cutoff point for positivity: $10 \mathrm{U} / \mathrm{mL}$ ). Antibody levels to five synthetic native peptides representing the bestestablished auto-antigens in RA [38] (that is, enolase-1 fibrinogen-1, fibrinogen-2, fibrinogen-3, and vimentin-1 and their citrullinated forms) were measured by using the same ELISA as described by van de Stadt and colleagues [39]. 
IgA, IgG, and IgM antibodies to $P$. gingivalis were determined by using an in-house developed ELISA, in which a pooled lysate of four randomly selected clinical isolates of $P$. gingivalis from patients with periodontitis was used as an antigen. These monocultures were suspended in ice-cold PBS with protease inhibitors (Complete Mini EDTA-free Protease Inhibitor Cocktail Tablets; Roche Diagnostics, Basel, Switzerland). After centrifuging and discarding of the supernatant, pellets were resuspended in an ice-cold lysis buffer containing non-denaturing detergent (Noninet P-40; Sigma-Aldrich, St. Louis, MO, USA) and sonicated for 15 minutes (Bioruptor Standard sonication device; Diagenode s.a., Liège, Belgium). Protein concentration was determined by using the BCA Protein Assay Kit (Pierce Protein Biology Products, Thermo Fisher Scientific, Rockford, IL, USA). Microtiter plates (Costar 96-Well; Corning, Amsterdam, The Netherlands) were coated overnight with $1 \mu \mathrm{g} / \mathrm{mL}$ of antigen. Standard curves were made from protein standard (N protein-standard SL; Siemens Healthcare Diagnostics, Den Haag, The Netherlands) diluted twofold (highest standard curve values were for 300, 25, and $250 \mathrm{ng} / \mathrm{mL}$ for IgA, IgG, and IgM, respectively). For the standard curves, the following capture antibodies were used: monoclonal anti-human IgA (1:4,000, clone GA112; Sigma-Aldrich, Zwijndrecht, The Netherlands), monoclonal anti-human IgM (1:10,000, clone MB-11, $\mu$ chain-specific; Sigma-Aldrich), and goat anti-human IgG $\left(1: 5,000, \mathrm{~F}(\mathrm{ab})_{2}\right.$ fragment-specific; Jackson ImmunoResearch Europe Ltd., Newmarket, UK), respectively. Serum samples were incubated in fourfold serial dilutions (1:100, 1:400, 1:1,600, and 1:6,400). Detection of anti- $P$. gingivalis antibodies was carried out with horseradish peroxidase-labeled goat anti-human IgA, mouse antihuman IgG (Fc fragment-specific, clone JDC-10), and mouse anti-human IgM ( $\mu$-chain-specific, clone SA-DA4; all from SouthernBiotech, Birmingham, AL, USA) followed by color reaction with tetramythylbenzidin and hydrogen peroxide. Absorbance was read at $450 \mathrm{~nm}$ in an EMax microplate reader and corrected for background binding, and concentration of antibodies was calculated by SOFTmax PRO software (Molecular Devices, Sunnyvale, CA, USA) according to the IgA, IgG, or IgM standard curves included on each ELISA plate and expressed in nanograms per milliliter. As an internal control, two serum samples with a repeatedly high and a low titer were tested at each plate. The variation coefficients were $22 \%$ for IgA, $20 \%$ for IgG, and 25\% for IgM anti-P. gingivalis. Interference of IgM-RF was investigated by spiking samples with sera with known high titers of RF. Adding RF had no measurable effect on anti- $P$. gingivalis titers.

In paired samples of serum and GCF of patients with $\mathrm{RA}$, the presence of IgG-ACPAs was assessed by using the anti-CCP2 ELISA (Euro Diagnostica, Nijmegen, The
Netherlands). Because the HLA-DRB1 shared epitope (SE) is a known genetic risk factor for RA and a possible genetic risk factor for periodontitis [40], HLA-DRB1-SEcontaining alleles were genotyped from genomic DNA in the patients with RA. The presence of an RA SE was analyzed by a polymerase chain reaction-based sequence-specific oligonucleotide probe hybridization (SSOP) approach by using a commercial kit (Hologic Gen-Probe Incorporated, San Diego, CA, USA) and Luminex xMAP technology (Luminex Corporation, Austin, TX, USA) in accordance with the instructions of the manufacturer.

\section{Microbiology}

Microbiological samples were processed by using standard anaerobic culture techniques $[41,42]$. Paper point samples were vortexed for 2 minutes, and appropriate 10 -fold serial dilutions $(100 \mu \mathrm{L})$ in PBS were plated on blood agar plates (Oxoid no. 2; Oxoid Limited, Basingstoke, UK), which were supplemented with horse blood (5\% vol/vol), hemin $(5 \mathrm{mg} / \mathrm{L})$, and menadione $(1 \mathrm{mg} / \mathrm{L})$ and incubated in $80 \% \mathrm{~N}_{2}, 10 \% \mathrm{H}_{2}$, and $10 \% \mathrm{CO}_{2}$ at $37^{\circ} \mathrm{C}$ for up to 14 days. Besides the presence and proportions of $P$. gingivalis, those of other established periodontal pathogens, including Prevotella intermedia, Fusobacterium nucleatum, Parvimonas micra, Tannerella forsythia, and Campylobacter rectus, were assessed [43]. Identification was based on microscopic morphology, Gram reaction, and the production of a set of metabolic enzymes (API/ID 32; BioMérieux, La Balme Les Grottes, France). Additional tests for identification included detection of a trypsin-like activity based on the degradation of benzoylDL-arginine-2-naphthylamide (Sigma-Aldrich) [44]. Finally, the total number of colony-forming units per sample was determined.

\section{Statistical analysis}

Data were analyzed by using GraphPad Prism 4 and Instat 3 (GraphPad Software, Inc., San Diego, CA, USA). For group comparisons among two groups, the unpaired two-tailed $t$ test for variables with normal distribution and the two-tailed Mann-Whitney test for skewed variables were used. For group comparisons among three groups, Kruskal-Wallis one-way analysis of variance was performed. The Fisher exact test or the chi-squared test for independence was used to analyze contingency tables. Significance level $\alpha$ was 0.05 .

\section{Results \\ Patients}

Two hundred thirty-nine consecutive patients with RA were invited to participate in this study. Of the 167 patients who provided written informed consent, 66 patients met at least one of the exclusion criteria. Of the 
101 included patients, six patients were excluded from analysis because of incomplete data. The final cohort consisted of 95 patients with RA. In addition, 203 consecutive patients were invited to join the control group. Of this group, 108 dentate persons without RA provided written informed consent. Twenty-eight of them had to be expelled on the basis of the exclusion criteria. The remaining 80 patients served as non-RA controls for blood and subgingival samples, matched for age, gender, BMI, and periodontal and smoking status $(n=44)$, or as healthy controls (no periodontitis and no cultivable $P$. gingivalis, $n=36$ ). Characteristics of the predominantly (99\%) Caucasian patients with RA, non-RA controls, and the healthy controls are summarized in Table 1. The general control population for estimating the prevalence of periodontitis consisted of 420 individuals matched for age and gender with the patients with RA (age of $56 \pm 5.5$ years, and $68 \%$ were female). The socioeconomic status of this group as assessed by the highest self-reported level of received education was comparable between the control population and the patients with RA (low: $27 \%$ versus $36 \%$, middle: $37 \%$ versus $30 \%$, and high: $36 \%$ versus $34 \%$ ).

\section{Periodontitis}

Forty-three percent of the patients with RA had moderate periodontitis, and $27 \%$ had severe periodontitis. These numbers are significantly higher than, respectively, the $18 \%$ and $12 \%$ found in the control population $(P<0.001)$. Compared with the control population, the relative risk for having RA and severe periodontitis was 3.7 (95\% confidence interval of 2.4 to 5.9 ) (Table 2).

RA patients with severe periodontitis had significantly higher DAS28 scores $(P<0.001)$ than RA patients with no or moderate periodontitis (Figure 1). CRP levels in RA patients with severe periodontitis were higher than in RA patients without periodontitis (marginally significant, $P=$ $0.05)$. In none of the DPSI categories was there a difference in DAS28 scores between smokers and non-smokers or former smokers. Also, no difference was found in RA disease duration, although patients with severe periodontitis were significantly older $(P<0.01)$. In the control population, there were no age differences between the DPSI categories.

\section{Presence of HLA-DRB1 shared epitope in patients with rheumatoid arthritis}

No differences were found in the presence or absence of the HLA-DRB1-SE in RA patients with no, moderate, or severe periodontitis $(n=78)$. In RA patients with no, moderate, or severe periodontitis, $58 \%, 66 \%$, and $62 \%$, respectively, were positive for HLA-DRB1-SE, and 29\%, $21 \%$, and $15 \%$, respectively, had two alleles.

\section{Serology}

Between RA patients with no, moderate, or severe periodontitis, no differences were seen in IgM-RF and ACPA levels or in reactivity against the citrullinated peptides enolase-1, fibrinogen-1, -2 , and -3 , and vimentin-1 (Figure 2). Between RA patients culture-positive or -negative for $P$. gingivalis, only reactivity against citrullinated fibrinogen-2 was different; reactivity was higher in $P$. gingivalis-positive patients $(P<0.01)$. A small number of RA patients with moderate $(n=2)$ or severe $(n=2)$ periodontitis and culture-positive for $P$. gingivalis had a higher reactivity against citrullinated $\alpha$-enolase compared with RA patients without periodontitis and without subgingival $P$. gingivalis. This $P$. gingivalis culture-positive subgroup also had high IgM-RF (mean $539 \pm 796 \mathrm{U} / \mathrm{mL}$ ), ACPAs (mean $340 \pm$ $0 \mathrm{U} / \mathrm{mL}$ ), and anti-P. gingivalis titers (IgM: mean $93 \pm 135$, IgG: $190 \pm 357$, IgA: $61 \pm 81 \mathrm{mg} / \mathrm{L})$.

Overall, patients with RA showed higher IgM anti- $P$. gingivalis titers compared with non-RA controls $(P<$ 0.05). There were no differences in anti-P. gingivalis titers between RA patients and non-RA controls with no or moderate periodontitis; however, RA patients with severe periodontitis showed both higher IgG and IgM anti- $P$. gingivalis titers compared with non-RA controls with severe periodontitis $(P<0.05)$ (Figure 3$)$. RA patients with moderate periodontitis have a less pronounced anti-P. gingivalis response compared with RA patients with severe periodontitis but a higher one than non-RA controls with severe periodontitis for IgG (borderline significant, $P=0.06)$ and $\operatorname{IgM}(P<0.05)$. Both RA patients and non-RA controls culture-positive for $P$. gingivalis showed higher anti-P. gingivalis titers compared with their culture-negative counterparts.

In patients with RA, serum levels of IgM-RF and ACPAs showed a strong correlation $(\rho=0.51, P<$

Table 2 Prevalence of periodontitis of rheumatoid arthritis patients compared with the age- and gender-matched control population

\begin{tabular}{lccc}
\hline DPSI category & $\begin{array}{c}\text { Patients with RA } \\
(\boldsymbol{n}=\mathbf{9 5})\end{array}$ & $\begin{array}{c}\text { Control population } \\
(\boldsymbol{n}=\mathbf{4 2 0})\end{array}$ & $\boldsymbol{P}$ value \\
\hline A: No periodontitis, percentage & 30 & 70 & $<0.001$ \\
\hline B: Moderate periodontitis, percentage & 43 & 18 & $<0.001$ \\
\hline C: Severe periodontitis, percentage & 27 & 12 & 3.6 \\
\hline
\end{tabular}

$\mathrm{Cl}$, confidence interval; DPSI, Dutch periodontal screening index; RA, rheumatoid arthritis. 
DAS28 $(p<0.001)$

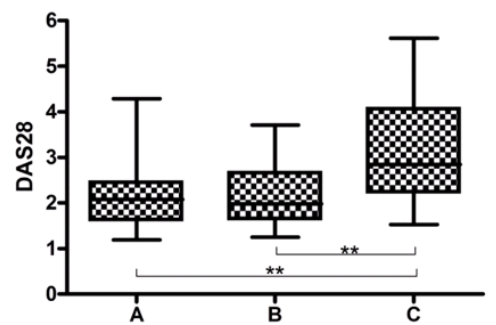

$\operatorname{CRP}(p=0.05)$

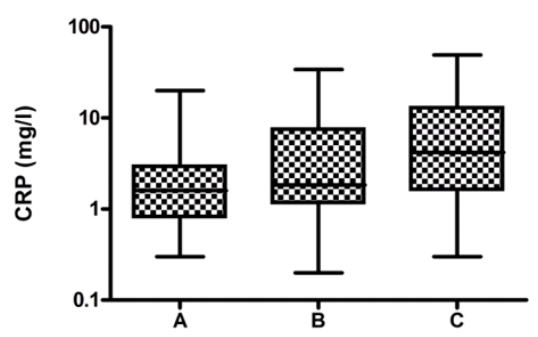

Figure 1 DAS28 scores and CRP levels in patients with rheumatoid arthritis and no (a), moderate (b), or severe (c) periodontitis. ${ }^{* *} P<$ 0.01 . CRP, C-reactive protein; DAS28, disease activity score 28 tender and swollen joint count.

$0.0001)$, as did IgG anti-P. gingivalis with IgM anti- $P$. gingivalis $(\rho=0.41, P<0.0001)$ and IgA anti- $P$. gingivalis $(\rho=0.66, P<0.0001)$. Medication used for RA was not of influence on $P$. gingivalis titers. In non-RA controls, IgG anti- $P$. gingivalis only correlated with IgA anti- $P$. gingivalis $(\rho=0.65, P<0.0001)$.

In patients with RA, there was a weak but significant correlation between IgM anti- $P$. gingivalis and IgM-RF $(\rho=0.33, P<0.01)$, ACPAs $(\rho=0.24, P<0.05)$, and the citrullinated peptides fibrinogen-1 $(\rho=0.27, P<$ $0.05)$ and fibrinogen-3 $(\rho=0.22, P<0.05)$. Likewise, IgG anti- $P$. gingivalis was correlated with IgM-RF ( $\rho=$ $0.26, P<0.05)$. In RA patients with severe periodontitis, there were no correlations between IgG, IgM, and IgA anti-P. gingivalis titers and IgM-RF and ACPAs. In patients with RA, ACPA levels in serum were comparable to ACPA levels in paired GCF samples which were not visibly contaminated with blood $(n=45, \rho=0.89$, $P<0.0001$ ) (Figure 4).

\section{Microbiology}

The subgingival prevalence of $P$. gingivalis was not different between patients with RA (16\%) and non-RA controls (20\%). In both groups, $P$. gingivalis was infrequently cultured in the absence of periodontitis (6\% to $12 \%$ ). None of the other identified periodontal pathogens differed in prevalence between RA patients and non-RA controls (P. intermedia: $66 \%$ versus $73 \%$, T. forsythia: $84 \%$ versus $70 \%, P$. micra: $88 \%$ versus $89 \%, F$. nucleatum: $100 \%$ versus $95 \%$, and C. rectus: $33 \%$ versus $41 \%$ ). However, the prevalence of anaerobic Gram-negative rods other than $P$. gingivalis and $P$. intermedia was higher in patients with RA (27\% versus $8 \%, P<0.05)$, as was the total bacterial load (in colony-forming units per milliliter) $(P<$ 0.05), notwithstanding the comparable mean probing pocket depth between RA patients and matched non-RA controls $(4.2 \pm 1.0 \mathrm{~mm})$.

\section{Discussion}

In this study, we found a significantly increased prevalence of periodontitis in RA patients and the highest RA disease activity in patients with severe periodontitis. Importantly, serological markers for systemic inflammation of periodontal origin further substantiated the connection of the two diseases in terms of higher antibody titers against $P$. gingivalis in RA patients with severe periodontitis compared with severe periodontitis patients without RA. These differences cannot be explained by differences in $P$. gingivalis colonization, since the distributions in RA and non-RA patients were similar.

Given that periodontitis is associated with only moderate elevations of CRP and erythrocyte sedimentation rate levels $[45,46]$, the higher DAS28 scores observed in RA patients with periodontitis can only partly be explained by these higher levels due to periodontitis. This is the first study that focused on anti-P. gingivalis titers in RA and non-RA controls, equally distributed in prevalence of $P$. gingivalis and periodontitis. We confirm elevated antibody titers against $P$. gingivalis in RA patients as reported in former studies; however, these studies did not consider the periodontal status or the microbiology of the patients with RA $[27,28]$. We found higher anti- $P$. gingivalis titers in RA patients compared with matched non-RA controls in cases of severe periodontitis. No differences in anti- $P$. gingivalis titers between these groups were found in cases of moderate periodontitis; however, RA patients with moderate periodontitis still had higher titers compared with severe periodontitis patients without RA. RA patients with cultivable $P$. gingivalis showed the highest anti- $P$. gingivalis titers, suggesting that RA amplifies the antibody response against $P$. gingivalis and that colonization of $P$. gingivalis could have contributed to the elevated titer, according to the fact that carriage of $P$. gingivalis is the strongest determinant of the systemic antibody response against this periodontal pathogen [47]. An explanation for the elevated anti- $P$. gingivalis titers could be a hyperinflammatory state of RA patients with periodontitis. ACPAs directed to citrullinated peptides of $P$. gingivalis could be another explanation for the elevated titers. Lundberg and colleagues [48] showed cross-reactivity of 
A.

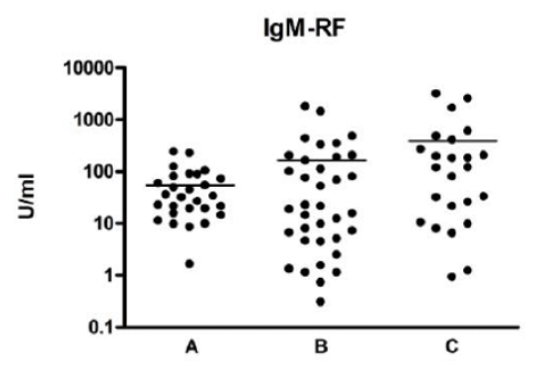

B.

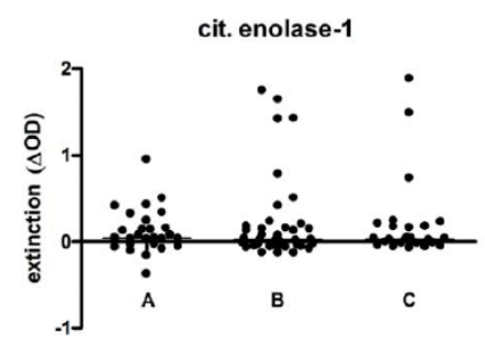

cit. fibrinogen-2

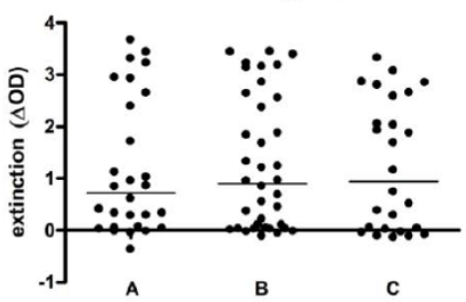

cit. vimentin-1

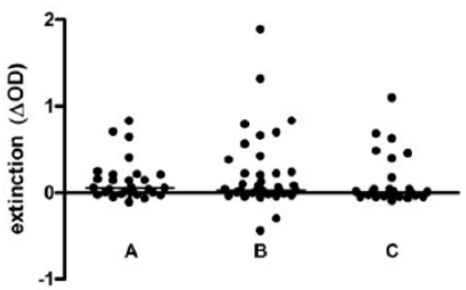

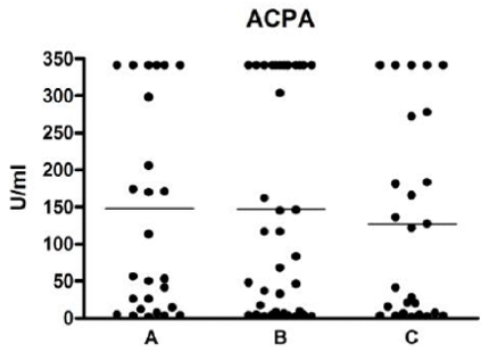

cit. fibrinogen-1

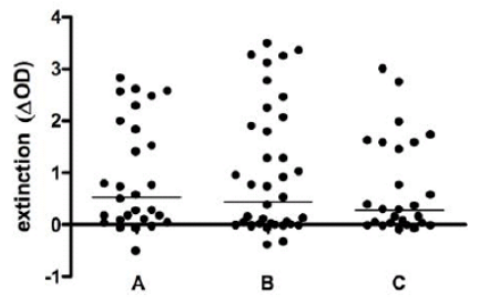

cit. fibrinogen-3

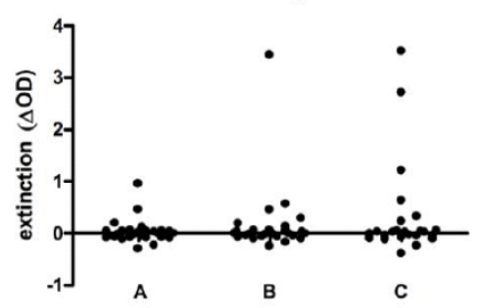

Figure 2 (A) IgM-RF and ACPA reactivity and (B) reactivity against five citrullinated (cit.) peptides in patients with rheumatoid arthritis and no (a), moderate (b), or severe (c) periodontitis. No significant differences were observed. $\triangle \mathrm{OD}$, optical density of the citrullinated form minus the native form of the peptide; ACPA, anti-citrullinated protein antibody; IgM-RF, immunoglobulin M-rheumatoid factor.

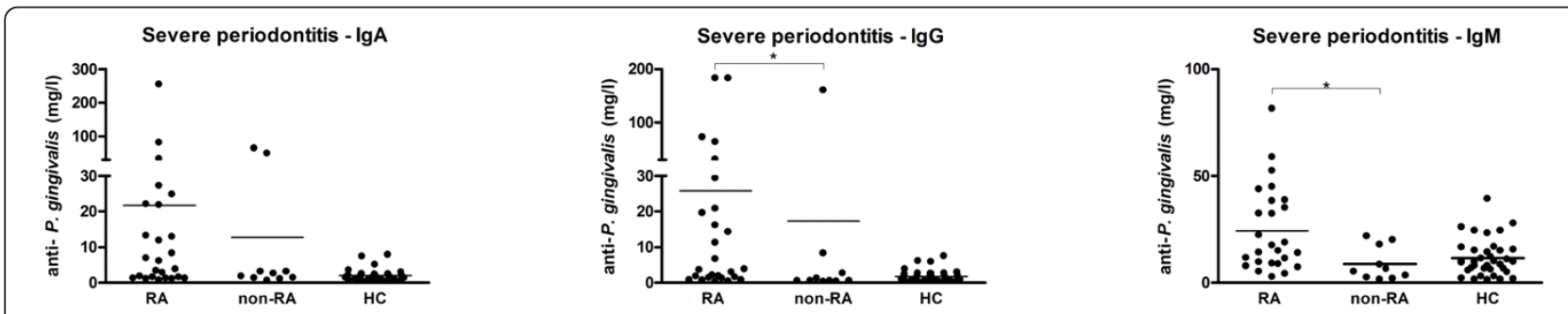

Figure $3 \lg A$, IgG, and $\lg M$ antibody response against Porphyromonas gingivalis in rheumatoid arthritis (RA) patients and non-RA controls with severe periodontitis as well as in healthy controls $(\mathrm{HC}) .{ }^{*} P<0.05$. Ig, immunoglobulin. 


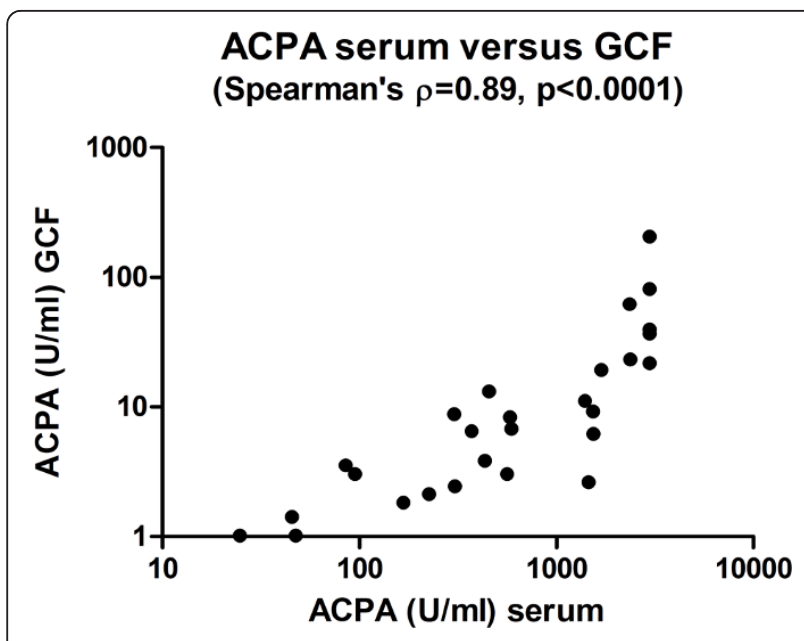

Figure 4 Correlation of anti-citrullinated protein antibody (ACPA) in paired samples of serum and gingival crevicular fluid (GCF) of patients with rheumatoid arthritis $(n=45)$.

human ACPAs with bacterial enolase. We found a high reactivity in a small subgroup of RA patients with periodontitis and culture-positive for $P$. gingivalis, but overall we found a weak correlation between ACPAs and anti- $P$. gingivalis titers. Whether anti- $P$. gingivalis antibodies are directed against the same epitopes as ACPAs needs further investigation. To consider whether elevated titers are specific for $P$. gingivalis, antibody titers to other periodontal bacteria should be assessed.

Little is known about oral colonization by $P$. gingivalis in patients with RA. We found no differences in the presence and proportions of any of the assessed periodontal pathogens between RA patients and non-RA controls; however, the prevalence of anaerobic Gram-negative rods other than $P$. gingivalis and $P$. intermedia was higher in patients with RA. Recently, Scher and colleagues [49] assessed the complete subgingival microbiota by pyrosequencing and detected $P$. gingivalis more frequently in recently diagnosed, never-treated RA patients $(n=25)$ in comparison with established RA patients or healthy controls; this finding, however, could be explained by the higher prevalence of severe periodontitis in those patients.

An association between the presence of periodontitis and ACPA or IgM-RF levels or both could not be established, in contrast to the findings of Dissick and colleagues [2], nor could we find differences in reactivity to the five synthetic citrullinated peptides between the DPSI categories, other than a higher reactivity against citrullinated peptide fibrinogen-2 in P. gingivalis culture-positive patients. As epitope spreading is related to RA disease duration [39], a widespread reactivity to different citrullinated peptides was found in our cohort with a relatively long disease duration. In future studies, the (temporal) relation of RA, periodontitis, and antibodies specific for RA should be performed in periodontitis patients, in nontreated RA patients, and/or in patients at risk for RA, ideally in a prospective follow-up study.

We found no differences in the presence or absence of the HLA-DRB1-SE in RA patients with no, moderate, or severe periodontitis, although this should be interpreted with some caution because of the small numbers of patients. The strong correlation between ACPA levels in serum and GCF, with lower levels in GCF, is suggestive of diffusion of ACPAs from plasma to GCF. Within the limitations of the method used in this study, we found no indication for local ACPA production in the periodontium.

\section{Conclusions}

We confirmed the previously reported disease association between RA and periodontitis and the increased prevalence of periodontitis in patients with RA. In addition, the severity of periodontitis appeared to be related to RA disease activity. Furthermore, severity of RA was not associated with cultivable $P$. gingivalis in established RA patients, although anti- $P$. gingivalis titers were higher in RA patients with severe periodontitis compared with matched non-RA subjects.

\section{Abbreviations}

ACPA: anti-citrullinated protein antibody; anti-CCP: anti-cyclic citrullinated protein; BMI: body mass index; CRP: C-reactive protein; DAS28: disease activity score 28 tender and swollen joint count; DPSI: Dutch periodontal screening index; ELISA: enzyme-linked immunosorbent assay; GCF: gingival crevicular fluid; PBS: phosphate-buffered saline; RA: rheumatoid arthritis; RF: rheumatoid factor; SE: shared epitope.

\section{Acknowledgements}

We thank Christelle Bal, of the Clinic for General Dental Practice Solwerd in Appingedam, The Netherlands, for providing their data for the control population and Annechien Lambeck, of the Department of Transplantation Immunology, University Medical Center Groningen, for HLA genotyping the cohort RA patients. This research was partly funded by the Jan Kornelis de Cock foundation (project number 11-71) and the foundation of the Dutch Periodontal Society.

\section{Author details}

${ }^{1}$ Center for Dentistry and Oral Hygiene, University of Groningen, University Medical Center Groningen, P.O. Box 30.001, 9700 RB Groningen, The Netherlands. ${ }^{2}$ Department of Rheumatology and Clinical Immunology, University of Groningen, University Medical Center Groningen, P.O. Box 30.001, 9700 RB Groningen, The Netherlands. ${ }^{3}$ Department of Oral and Maxillofacial Surgery, University of Groningen, University Medical Center Groningen, P.O. Box 30.001, 9700 RB Groningen, The Netherlands. ${ }^{4}$ Department of Medical Microbiology, University of Groningen, University Medical Center Groningen, P.O. Box 30.001, 9700 RB Groningen, The Netherlands.

\section{Authors' contributions}

All authors were involved in drafting the article or revising it critically for important intellectual content, and all authors approved the final version to be published. All authors were involved in study conception and design. Acquisition and analysis of data were carried out by MdS, JW, EB, and BDvdM, who take responsibility for the integrity of the data and the accuracy of the data analysis. 


\section{Competing interests}

The authors declare that they have no competing interests.

Received: 18 May 2012 Revised: 10 September 2012

Accepted: 25 September 2012 Published: 17 October 2012

\section{References}

1. De Pablo P, Dietrich T, McAlindon TE: Association of periodontal disease and tooth loss with rheumatoid arthritis in the US population. $J$ Rheumatol 2008, 35:70-76.

2. Dissick A, Redman RS, Jones M, Rangan BV, Reimold A, Griffiths GR, Mikuls TR, Amdur RL, Richards JS, Kerr GS: Association of periodontitis with rheumatoid arthritis: a pilot study. J Periodontol 2010, 81:223-230.

3. Kasser UR, Gleissner C, Dehne F, Michel A, Willershausen-Zonnchen B, Bolten WW: Risk for periodontal disease in patients with longstanding rheumatoid arthritis. Arthritis Rheum 1997, 40:2248-2251.

4. Nesse W, Dijkstra PU, Abbas F, Spijkervet FKL, Stijger A, Tromp JAH, van Dijk JL, Vissink A: Increased prevalence of cardiovascular and autoimmune diseases in periodontitis patients: a cross-sectional study. $J$ Periodontol 2010, 81:1622-1628.

5. Pischon N, Pischon T, Kröger J, Gülmez E, Kleber BM, Bernimoulin JP, Landau H, Brinkmann PG, Schlattmann P, Zernicke J, Buttgereit F, Detert J: Association among rheumatoid arthritis, oral hygiene, and periodontitis. J Periodontol 2008, 79:979-986.

6. Tolo $K$, Jorkjend $L$ : Serum antibodies and loss of periodontal bone in patients with rheumatoid arthritis. J Clin Periodontol 1990, 17:288-291.

7. Mercado FB, Marshall RI, Klestov AC, Bartold PM: Relationship between rheumatoid arthritis and periodontitis. I Periodontol 2001, 72:779-787.

8. Mercado F, Marshall RI, Klestov AC, Bartold PM: Is there a relationship between rheumatoid arthritis and periodontal disease? J Clin Periodontol 2000, 27:267-272.

9. Nesse W, Abbas F, van der Ploeg I, Spijkervet FKL, Dijkstra PU, Vissink A: Periodontal inflamed surface area: quantifying inflammatory burden. $J$ Clin Periodontol 2008, 35:668-673.

10. Susanto H, Nesse W, Dijkstra PU, Agustina D, Vissink A, Abbas F: Periodontitis prevalence and severity in Indonesians with type 2 diabetes. J Periodontol 2011, 82:550-557.

11. Barksby HE, Lea SR, Preshaw PM, Taylor JJ: The expanding family of interleukin-1 cytokines and their role in destructive inflammatory disorders. Clin Exp Immunol 2007, 149:217-225.

12. Berthelot JM, Le Goff B: Rheumatoid arthritis and periodontal disease. Joint Bone Spine 2010, 77:537-541.

13. Culshaw S, Mclnnes IB, Liew FY: What can the periodontal community learn from the pathophysiology of rheumatoid arthritis? I Clin Periodontol 2011, 38(Suppl 11):106-113.

14. Detert J, Pischon N, Burmester GR, Buttgereit F: The association between rheumatoid arthritis and periodontal disease. Arthritis Res Ther 2010, 12:218.

15. Getts MT, Miller SD: 99th Dahlem conference on infection, inflammation and chronic inflammatory disorders: triggering of autoimmune diseases by infections. Clin Exp Immunol 2010, 160:15-21.

16. Rosenstein ED, Greenwald RA, Kushner L, Weissmann G: Hypothesis: the humoral immune response to oral bacteria provides a stimulus for the development of rheumatoid arthritis. Inflammation 2004, 28:311-318

17. McGraw WT, Potempa J, Farley D, Travis J: Purification, characterization and sequence analysis of a potential virulence factor from Porphyromonas gingivalis, peptidylarginine deiminase. Infect Immun 1999, 67:3248-3256

18. Lundberg K, Wegner N, Yucel-Lindberg T, Venables PJ: Periodontitis in RAthe citrullinated enolase connection. Nat Rev Rheumatol 2010, 6:727-730.

19. György B, Tóth E, Tarcsa E, Falus A, Buzás El: Citrullination: a posttranslational modification in health and disease. Int J Biochem Cell Biol 2006, 38:1662-1677.

20. Avouac J, Gossec L, Dougados M: Diagnostic and predictive value of anticyclic citrullinated protein antibodies in rheumatoid arthritis: a systematic literature review. Ann Rheum Dis 2006, 65:845-851.

21. Nishimura K, Sugiyama D, Kogata Y, Tsuji G, Nakazawa T, Kawano S, Saigo K, Morinobu A, Koshiba M, Kuntz KM, Kamae I, Kumagai S: Meta-analysis: diagnostic accuracy of anti-cyclic citrullinated peptide antibody and rheumatoid factor for rheumatoid arthritis. Ann Intern Med 2007, 146:797-808
22. Nielen MM, van Schaardenburg D, Reesink HW, van de Stadt RJ, van der Horst-Bruinsma IE, de Koning MH, Habibuw MR, Vandenbroucke JP, Dijkmans BA: Specific autoantibodies precede the symptoms of rheumatoid arthritis: a study of serial measurements in blood donors. Arthritis Rheum 2004, 50:380-386.

23. van der Helm-van Mil AH, Verpoort KN, Breedveld FC, Toes RE, Huizinga TW: Antibodies to citrullinated proteins and differences in clinical progression of rheumatoid arthritis. Arthritis Res Ther 2005, 7:R949-R958.

24. Castillo DM, Sanchez-Beltran MC, Castellanos JE, Sanz I, Mayorga-Fayad I, Sanz M, Lafaurie Gl: Detection of specific periodontal microorganisms from bacteraemia samples after periodontal therapy using molecularbased diagnostics. J Clin Periodontol 2011, 38:418-427.

25. D'Aiuto F, Graziani F, Tete S, Gabriele M, Tonetti MS: Periodontitis: from local infection to systemic diseases. Int I Immunopathol Pharmacol 2005, 18:1-11.

26. Hitchon CA, Chandad F, Ferucci ED, Willemze A, loan-Facsinay A, van der Woude D, Markland J, Robinson D, Elias B, Newkirk M, Toes RM, Huizinga TW, El-Gabalawy HS: Antibodies to Porphyromonas gingivalis are associated with anticitrullinated protein antibodies in patients with rheumatoid arthritis and their relatives. J Rheumatol 2010, 37:1105-1112.

27. Mikuls TR, Payne JB, Reinhardt RA, Thiele GM, Maziarz E, Cannella AC, Holers VM, Kuhn KA, O'Dell JR: Antibody responses to Porphyromonas gingivalis ( $P$. gingivalis) in subjects with rheumatoid arthritis and periodontitis. Int Immunopharmacol 2009, 9:38-42.

28. Ogrendik M, Kokino S, Ozdemir F, Bird PS, Hamlet S: Serum antibodies to oral anaerobic bacteria in patients with rheumatoid arthritis. MedGenMed 2005, 7:2.

29. Nesse W, Westra J, van der Wal JE, Abbas F, Nicholas AP, Vissink A, Brouwer $E$ : The periodontium of periodontitis patients contains citrullinated proteins which may play a role in ACPA (anti-citrullinated protein antibody) formation. J Clin Periodontol 2012, 39:599-607.

30. Arnett FC, Edworthy SM, Bloch DA, McShane DJ, Fries JF, Cooper NS, Healey LA, Kaplan SR, Liang MH, Luthra HS, Medsger TA, Mitchell DM, Neustadt DH, Pinals RS, Schaller JG, Sharp JT, Wilder RL, Hunder GG: The American Rheumatism Association 1987 revised criteria for the classification of rheumatoid arthritis. Arthritis Rheum 1988, 31:315-324.

31. Jansson H: Studies on periodontitis and analyses of individuals at risk for periodontal diseases. Swed Dent J Supp/ 2006, 180:5-49.

32. Van der Velden U: The Dutch periodontal screening index validation and its application in The Netherlands. J Clin Periodontol 2009, 36:1018-1024.

33. Broer J, Kuiper J, Spijkers J: Health Profile Groningen 2010 Groningen, The Netherlands: Muncipal Health Department; 2011, 11-17.

34. Prevoo ML, van 't Hof MA, Kuper $H H$, van Leeuwen MA, van de Putte $L B$, van Riel PL: Modified disease activity scores that include twenty-eightjoint counts. Development and validation in a prospective longitudinal study of patients with rheumatoid arthritis. Arthritis Rheum 1995, 38:44-48.

35. Mombelli A, McNabb H, Lang NP: Black-pigmenting gram-negative bacteria in periodontal disease. II. Screening strategies for detection of P. gingivalis. J Periodontal Res 1991, 26:308-313.

36. Syed SA, Loesche WJ: Survival of human dental plaque flora in various transport media. Appl Microbiol 1972, 24:638-644.

37. van Leeuwen MA, Westra J, van Riel PL, Limburg PC, van Rijswijk MH: IgM $\lg A$, and $\lg G$ rheumatoid factors in early rheumatoid arthritis predictive of radiological progression? Scand J Rheumatol 1995, 24:146-153.

38. Wegner N, Lundberg K, Kinloch A, Fisher B, Malmström V, Feldmann M, Venables PJ: Autoimmunity to specific citrullinated proteins gives the first clues to the etiology of rheumatoid arthritis. Immunol Rev 2010, 233:34-54.

39. van de Stadt $L A$, van der Horst AR, de Koning MH, Bos WH, Wolbink GJ, van de Stadt RJ, Pruijn GJ, Dijkmans BA, van Schaardenburg D, Hamann D: The extent of the anti-citrullinated protein antibody repertoire is associated with arthritis development in patients with seropositive arthralgia. Ann Rheum Dis 2011, 70:128-133.

40. Bonfil JJ, Dillier FL, Mercier P, Reviron D, Foti B, Sambuc R, Brodeur JM Sedarat C: A "case control" study on the role of HLA DR4 in severe periodontitis and rapidly progressive periodontitis. Identification of types and subtypes using molecular biology (PCR.SSO). I Clin Periodontol 1999, 26:77-84

41. Boutaga K, van Winkelhoff AJ, Vandenbroucke-Grauls CM, Savelkoul PH: The additional value of real-time PCR in the quantitative detection of periodontal pathogens. J Clin Periodontol 2006, 33:427-433. 
42. van Winkelhoff AJ, Clement M, De Graaff J: Rapid characterization of oral and nonoral pigmented Bacteroides species with the ATB Anaerobes ID system. J Clin Microbiol 1988, 26:1063-1065.

43. Zambon JJ: Periodontal diseases: microbial factors. Ann Periodontol 1996, 1:879-925.

44. van Winkelhoff AJ, van Steenbergen TJ, Kippuw N, De Graaff J: Further characterization of Bacteroides endodontalis, an asaccharolytic blackpigmented Bacteroides species from the oral cavity. J Clin Microbiol 1985, 22:75-79.

45. Noack B, Genco RJ, Trevisan M, Grossi S, Zambon JJ, de Nardin E: Periodontal infections contribute to elevated systemic C-reactive protein level. J Periodontol 2001, 72:1221-1227.

46. Hutter JW, van der Velden U, Varoufaki A, Huffels RA, Hoek FJ, Loos BG: Lower numbers of erythrocytes and lower levels of hemoglobin in periodontitis patients compared to control subjects. J Clin Periodontol 2001, 28:930-936.

47. Pussinen PJ, Könönen E, Paju S, Hyvärinen K, Gursoy UK, Huumonen S, Knuuttila M, Suominen AL: Periodontal pathogen carriage, rather than periodontitis, determines the serum antibody levels. $J$ Clin Periodontol 2011, 38:405-411.

48. Lundberg K, Kinloch A, Fisher BA, Wegner N, Wait R, Charles P, Mikuls TR, Venables PJ: Antibodies to citrullinated alpha-enolase peptide 1 are specific for rheumatoid arthritis and cross-react with bacterial enolase. Arthritis Rheum 2008, 58:3009-3019.

49. Scher JU, Ubeda C, Equinda M, Khanin R, Buischi Y, Viale A, Lipuma L, Attur M, Pillinger MH, Weissmann G, Littman DR, Pamer EG, Bretz WA, Abramson SB: Periodontal disease and the oral microbiota in new-onset rheumatoid arthritis. Arthritis Rheum 2012, 64:3083-3094.

doi:10.1186/ar4061

Cite this article as: Smit et al:: Periodontitis in established rheumatoid arthritis patients: a cross-sectional clinical, microbiological and serological study. Arthritis Research \& Therapy 2012 14:R222.

\section{Submit your next manuscript to BioMed Central and take full advantage of:}

- Convenient online submission

- Thorough peer review

- No space constraints or color figure charges

- Immediate publication on acceptance

- Inclusion in PubMed, CAS, Scopus and Google Scholar

- Research which is freely available for redistribution

Submit your manuscript at www.biomedcentral.com/submit
Biomed Central 